\title{
HOW TO MODERNIZE THE ACADEMIC MUSEUM. EXHIBITION ACTIVITY OF THE MUSEUM GROUP THE ARAS AS A PILOT PROJECT OF THE MUSEUM OF HISTORY OF RUSSIAN ACADEMY OF SCIENCE ${ }^{1}$
}

\author{
Irina A. Korneva-Chaeva \\ Archive of Russian Academy of Sciences, Moscow, Russian Federation \\ Natalia P. Rybkina \\ Archive of Russian Academy of Sciences, Moscow, Russian Federation
}

\begin{abstract}
The article on the example of the Museum group of Archives of Russian Academy of Science is demonstrating new possibilities of representation of archival documents in the museum space. The authors focused on the potential exposure of the museum based on the principle of visualization. They explain the special role of representing scientific knowledge for education of youth. They offer a new form of interactive communication with the museum's scientific heritage, based on the method of comprehending the reality as a "co-experience" and "re-discovery" that leads to the attainment the new generation to the new intellectual and spiritual experience. The experiment, the research paper, the science, the war, and even the modern art are the main themes of our exhibitions. The authors use the special new methods of exhibition to create the intriguing image of scientist. They use light boxes and interactive demonstrations. The main aim of the exposition is to show the documents of Archives of Russian Academy of Science, so we rely on the following materials: personal fond of academicians A.N. Nesmeyanov, V.L. Komarov, M.V. Keldysh, I.V. Kurchatov and others. Authors successfully solve the problems of the development of new theoretical principles exposing archival documents by modern methods.
\end{abstract}

Key words: history of science, museum, Academy of Sciences, museum space, archive.

УДК 168.522

ББК $79.17+л 6$
Дата поступления статьи: 07.12.2015

Дата принятия статьи: 06.05.2016

\section{КАК СДЕЛАТЬ АКАДЕМИЧЕСКИЙ МУЗЕЙ СОВРЕМЕННЫМ. ВЫСТАВОЧНАЯ ДЕЯТЕЛЬНОСТЬ МУЗЕЙНОЙ ГРУППЫ АРАН КАК ПИЛОТНЫЙ ПРОЕКТ МУЗЕЯ ИСТОРИИ РОССИЙСКОЙ АКАДЕМИИ НАУК ${ }^{1}$}

\author{
Ирина Анатольевна Корнева-Чаева \\ Архив РАН, г. Москва, Российская Федерация \\ Наталья Платоновна Рыбкина \\ Архив РАН, г. Москва, Российская Федерация
}

Аннотация. В данной статье на примере работы Музейной группы Архива РАН демонстрируются новые возможности репрезентации архивных документов в музейном пространстве и популяризации научного знания для разных категорий зрителей.

Ключевые слова: история науки, музей, Академия наук, выставочное пространство, архив. 
В апреле 2008 г. Президиум Российской академии наук принял решение о создании Музея истории академии наук [9]. Осуществлять научно-методическое руководство проектом было поручено Архиву РАН, одному из старейших учреждений российской науки, в котором, помимо документов, хранится коллекция мемориальных предметов, связанных с именами выдающихся ученых. В 2012 г. была сформирована Музейная группа, задачами которой стало не только комплектование и учет музейного фонда, но и создание концепции Музея истории Академии наук и проведение выставок, выполняющих функции пилотного проекта будущего Музея. В основу концепции положена идея формирования в обществе целостного представления о развитии отечественной фундаментальной науки и Академии наук как ее авангарда, занимающего почетное место среди крупнейших научных учреждений в мире, о ее значении в мировом научном процессе и развитии России в целом [11].

Сегодня музеи РАН составляют одну из самых крупных музейных сетей в нашей стране, включающую более 100 музеев и музейных объектов [6]. Среди них можно выделить лишь три полноценно функционирующих академических музея - Кунсткамера, Минералогический музей им. Ферсмана, Геологический музей им. Вернадского [6]. Остальные музеи, играя роль научно-вспомогательных подразделений учреждений РАН, популяризируют научные коллекции главным образом среди научного сообщества. По мнению В.Ю. Афиани, директора Архива РАН, члена Музейного совета РАН, со временем «новый музей должен найти и занять свою нишу» в сети академических музеев [5].

Сегодня, на этапе создания концепции в эпоху реформ социальных институтов, и прежде всего самой Академии, Музей рассматривается как академическое учреждение для реализации образовательно-просветительной деятельности, обращенной к массовому зрителю; как место для экспозиции, отражающее основные этапы становления РАН и ее достижения как выдающегося организационного центра фундаментальных и прикладных исследований в России [11]; как научно-исследовательский центр, изучающий институциональную составляющую Академии наук и ее взаимодействие с государством. Необходимо отойти от «сплошного научно-технического аттракциона» [5], заниматься изучением музейной аудитории, поиском форм работы, как с целой экспозицией, так и с отдельными музейными предметами, применять интерактивный подход. Музейная группа останавливает свой выбор на феноменологическом подходе, базирующемся на теории коммуникации как междисциплинарной концепции передачи информации [10]. На примере работы Музейной группы мы наблюдаем процесс слияния двух институтов социальной памяти - Архива и Музея.

За короткий срок существования Музейной группы осуществлены пять выставок, реализованы две образовательные программы. Основной целью организаторов выставок стала разработка методологии презентации огромного наследия старейшего отечественного архива, что позволяет, опираясь на фонды Архива, выйти за рамки чисто академической среды $[2 ; 11]$.

11 октября 2014 г. открылась музейно-документальная выставка «Я взялся за эксперимент», посвященная жизни выдающегося ученого, химика-органика, Президента АН СССР Александра Николаевича Несмеянова (18991980). Благодаря дару Института элементоорганических соединений РАН, основанного Несмеяновым, воссоздан рабочий кабинет ученого 1950-х гг. - один из важных разделов будущей экспозиции Музея, который уже сегодня используется как площадка для проведения интерактивных занятий с детьми школьного возраста. Так, экскурсии, посвященные феномену документа, начинаются с совместного чтения письма, лежащего на письменном столе «ученого», в котором академик Несмеянов, обращаясь к учащимся третьего класса, обосновывает необходимость получения образования [8].

Разрабатывая форму презентации научного наследия, сотрудники Музейной группы изучают потенциал системы музейного экспонирования, базирующейся на принципе визуализации. В связи с этим мы решили обратиться к современному актуальному искусству и организовать выставку «Искусство новых технологий».

Во 2-й половине прошлого столетия произошел прорыв в сфере технологий изобразительного искусства, позволивший значительно расширить традиционный набор материалов и техник тем художникам, которым уже не хва- 
тало масла на холсте, металла и камня в скульптуре. Изменилась видовая и жанровая структура современного искусства, возникли новые формы синтеза в сфере визуальности, объединяющие живопись, кино, фотографию, литературу, философию и научные достижения. На стыке науки, искусства и технологий началось формирование новой трансдисциплинарной области, получившей название «сайнс-арт», или «научное искусство», в рамках которого осуществляется «синтез дискурсивного мышления и интуитивного суждения» [7]. Это дает возможность усилить наглядность некоторых музейных объектов и воспринимать их с эстетической точки зрения. Такая практика уже применяется авторами мультимедийных и интерактивных научных проектов, например, в Музее науки «Нижегородская радиолаборатория».

В выставке, организованной Музейной группой Архива Российской академии наук, приняли участие художники, уже успевшие стать классиками современного искусства: Франциско Инфанте и Нонна Горюнова, Гор Чахал, Татьяна Баданина, Владимир Наседкин, Татьяна и Сергей Костриковы, Ольга Чернышова. Творчество всех представленных авторов опирается на научные открытия, все они тяготеют к метафоре, используя для этого неклассические с точки зрения традиционного искусства средства - арт-объекты в инсталляциях, видео- и фото-арт, - таким образом демонстририруя научную оснащенность художественного высказывания. Ольга Чернышова, обращаясь к видео-арту, исследует повседневную жизнь России с ее неосознанными желаниями, оговорками, случайностями и несбывшимися надеждами. Инсталляции и оптические объекты Татьяны Баданиной эстетизируют тему природного разложения белого цвета в спектр. Гор Чахал обращается к традиции сакрального искусства - Литургия, Фаворский Свет, Божественные энергии, пространство иконы стали темами его композиций, выполненных в технике компьютерной живописи. Будучи дипломированным специалистом в области прикладной математики, художник использует научный инструментарий для создания особого «приборного зрения», необходимого для восприятия сущности образа. Он изобрел новый способ фотосъемки, при котором используется линза Френеля для достиже- ния эффекта обратной перспективы, укоренившейся в традиции иконописания.

Самыми перспективными для научной экспозиции работами сайнс-арта мы считаем те, в которых художники от метафоричности художественного образа переходят к прямой демонстрации сущности физического явления и красоты научного эксперимента. Образцом могут служить инсталляции Эвелины Домнич и Дмитрия Гельфанда, активных организаторов и участников выставок этого профиля, выступающих как теоретики с курсом лекций на микрофакультете наукоискусства Академии художеств в Гааге. В обновленной экспозиции Политехнического музея, открытой в павильоне ВДНХ на время реконструкции главного здания, есть несколько визуальных и аудиовизуальных инсталляций, обладающих высокой степенью наглядности, но уступающих проектам Домнич - Гельфанда своими художественными качествами (примером дидактической визуальной инсталляции из экспозиции Политехнического музея на ВДНХ может служить работа Ольги Иноземцевой и Алексея Корзухина «Оцифровка воды»). Мы полагаем, что авторские коллективы Политехнического музея и Музейной группы АРАН, несмотря на существующую на сегодняшний день разницу в их возможностях, осуществляют поиски новых форм экспонирования в общем русле.

Выставка «Документ. От бересты к научному труду» открылась в декабре 2014 года. Перед ее авторами стояла задача поиска новых форм интерактивной демонстрации, позволяющих исследовать историю и развитие науки, а также изучения и формирования зрительской аудитории будущего Музея. Уникальность проекта заключается в том, что это первая выставка, посвященная развитию документа, ориентированная на широкий круг зрителей, но адресованная школьникам 1-7 классов. Она состоит из 12 разделов, включающих в себя редко экспонируемые материалы Архива РАН, древние и современные носители письменности, чертежи XVIII-XX вв., рисунки, карты, объемные макеты и 2 интерактивные инсталляции [1]. «Структура выставки отражает многообразие исторического контекста развития документа и демонстрирует путь возникновения и движения письменности, ее развитие в России параллельно с научными знаниями, наукой» $[1$, с. 36]. При создании экспозиции ее 
авторы опирались на метод содержательного кластера, позволяющий наиболее ярко и выразительно раскрывать тематику разделов выставки, каждый из которых представлен отдельным лайт-боксом, стендом и витриной [1]. Интерактивной составляющей выставки стала возможность, во-первых, провести самостоятельные исследования, опираясь на материалы экспозиции, и, во-вторых, попробовать написать своими руками текст писалом на цере или гусиным пером на бумаге, а также принять участие в реставрации бумаги в Реставрационной лаборатории Архива РАН под руководством опытных специалистов. Ознакомление со стендом «Носители информации», разработанным членом-корреспондентом РАН, доктором исторических наук В.П. Козловым, помогает определить самый популярный носитель информации в разные исторические периоды в России, назвать факторы, влияющие на популярность материального носителя, и принять участие в дискуссии на тему: «Сохранится ли в будущем бумага как носитель информации» [1, с. 37; 3].

Сотрудники Музейной группы Архива РАН разрабатывают методические приемы для пробуждения интереса у детской аудитории к таким сложным темам, как научные биографии (начиная с биографии М.В. Ломоносова), история Академии наук, забытые имена в отечественной науке, развитие различных областей науки и техники [1]. Особенной популярностью у наших зрителей пользуется раздел, посвященный развитию оптики, начиная от реконструированной камеры-обскуры и заканчивая голографической композицией современного художника Константина Худякова. Мы полагаем, что успешная коммуникация на экспозиции «Документ» «может стать для школьников, стоящих перед выбором профессии, мощным имиджевым фактором в пользу привлекательности научного образа жизни, научной картины мира, научного поиска» [1, с. 38].

Одна из удач Музейного отдела - выставка «Наука и война», которая прошла с 20 апреля по 20 мая 2015 года. На ней были представлены редко экспонируемые материалы из Архива РАН: документы из фондов Президента Академии наук в годы войны В.Л. Комарова, возглавлявшего Комиссию по мобилизации ресурсов Урала на нужды обороны страны; С.П. Королева, произ- водившего в 1944 г. испытания ракетных ускорителей; И.В. Курчатова, родоначальника советского атомного проекта; М.В. Келдыша, получившего в 1942 г. Сталинскую премию за научные работы по предупреждению разрушения самолетов вследствие флаттера крыльев и хвостового оперения; и др. Композиция лайтбокса «Все для фронта, все для победы!» стала первым опытом по созданию мини-энциклопедии научных открытий во время войны.

Осенью 2015 г. стартовал совместный проект Архива РАН и Ботанического сада биофака МГУ «Путем Петра», который позволит будущему Музею истории РАН, опираясь на потенциал раритетов, выйти за рамки чисто академической среды и установить прямой диалог с молодым поколением. Главная цель проекта - научить детей младшего и среднего школьного возраста (8-13 лет) изучать окружающий мир, используя научный инструментарий, современные информационные технологии и акварели XVII в., хранящиеся в Архиве РАН. В рамках проекта проводятся занятия, посвященные изучению жизненных циклов представителей флоры и фауны, на основе которых школьникам предлагается провести наблюдение за постепенным развитием растений и насекомых и фиксировать (рисовать или фотографировать) этапы этих изменений, используя в качестве примера акварели голландской художницы и исследовательницы Марии Сибиллы Мериан (1647-1717), привезенные в Россию Петром I как методическое пособие для художников, обучающихся в Академии художеств. Планируется проведение совместной интерактивной выставки акварелей Марии Сибиллы Мериан [4] и лучших работ школьников на территории Ботанического сада МГУ. На основе видеозаписей предполагается создание образовательной программы для социально отверженных детей из детских домов как целевой аудитории. Эта форма противостояния их социальной отверженности признана одной из важнейших функций современного музея. Проект предлагает новую интерактивную форму музейной коммуникации с научно-музейным наследием, основанную на таком способе постижения реальности, как «сопереживание» и «переоткрытие», что ведет к обретению детьми нового интеллектуального и духовного опыта. 
Таким образом, выставочная деятельность Музейной группы Архива РАН за трехлетний период ее существования являет собой начальный этап реализации концептуальной модели современного академического музея как многофункционального социокультурного центра, укорененного в академической научной среде и транслирующего идеи современности. Нами апробируются новые методы и формы презентации архивных документов в музейном пространстве, демонстрации и популяризации научного знания среди разных категорий зрителей, и прежде всего молодежи и школьников. Мы надеемся, что к предстоящему 300-летию РАН Музей истории Российской академии наук получит отдельное здание и будет твердо стоять на ногах [5].

\section{ПРИМЕЧАНИЕ}

1 Работа выполнена при поддержке гранта РГНФ № 14-03-00238 «История академической науки в России как междисциплинарное комплексное музейное исследование».

\section{СПИСОК ЛИТЕРАТУРЫ}

1. Бодрова, М. Л. Концепция и принципы экспонирования выставки «Документ. От бересты к научному труду» в Архиве Российской академии наук / М. Л. Бодрова, И. А. Корнева-Чаева, Н. П. Рыбкина // Исторические, философские, политические и юридические науки, культурология и искусствоведение. Вопросы теории и практики. Тамбов : Грамота, 2015. - № 2 (52), ч. II. - С. 35-38.

2. Илизаров, С. С. Начала русской научной литературы (обоснование в трудах Миллера) / С. С. Илизаров // ВИЕТ (Вопросы истории естествознания и техники). - 2010. - № 2. - С. 5-91.

3. Козлов, В. П. Аннотация / В. П. Козлов // История письма, документа и архивного дела в России : в 3 ч. / науч. рук. В. П. Козлов ; Росархив, ВНИИДАД. - Электрон. дан. - М., 2010. - Загл. с титул. экрана.

4. Копанева, Н. П. Акварели Марии Сибиллы Мериан в Санкт-Петербургском филиале Архива Российской Академии наук: «Мне захотелось представить... божественное чудо» / Н. П. Копанева. Электрон. текстовые дан. - Режим доступа: http:// www.arran.ru/data/collections/col9_.pdf(дата обращения: 20.07.2015). - Загл. с экрана.

5. Мойст, В. «Аттракциона у нас не будет, и циклотрон в экспозиции не поместится» : интер- вью с инициатором создания музея Российской академии наук, директором Архива РАН Виталием Афиани / В. Мойст. - Электрон. текстовые дан. 08.08.2013. - Режим доступа: https://www.gazeta.ru/ culture/2013/08/08/a 5546897.shtml (дата обращения: 13.08.2013). - Загл. с экрана.

6. Мурзинцева, А. Е. Музеи Российской академии наук: историко-культурологический анализ / А. Е. Мурзинцева // Dslib.net : Библиотека диссертаций. Библиотека диссертаций и авторефератов России dslib.net. - Электрон. дан. - Режим доступа: http://www.dslib.net (дата обращения: 20.07.2015). Загл. с экрана.

7. Научное искусство : тезисы I Международной научно-практической конференции, МГУ им. Ломоносова, 4-5 апр. 2012 г. / под ред. В. В. Миронова. - М. : МИЭЭ, 2012.

8. Несмеянов, А. Н. Письма учащимся о необходимости получения образования / А. Н. Несмеянов // Архив Российской академии наук. Ф. 1647. - Оп. 1. - Д. 229.

9. Постановление Президиума РАН № 316 от 29.04.2008 о состоянии и дополнительном финансировании музеев Российской академии наук. Электрон. дан. - Режим доступа: http://www.ras.ru/ presidium/documents/directions.aspx?ID $=3504 \mathrm{~b} 0 \mathrm{a} 0$ 851c-4610-90be-66el c9729 fd6\&print=1 (дата обращения: 25.07.2015). - Загл. с экрана.

10. Пшеничная, С. В. Концептуальная модель музея в современной отечественной музеологии / С. В. Пшеничная // Государственный музей-памятник «Исаакиевский собор» : [сайт]. Музеи России: поиски, исследования, опыт работы : сборник научных трудов. 2007. № 9. - Электрон. текстовые дан. - Режим доступа: http://isaak.spb.ru/digest/ num9/pshen (дата обращения: 22.07.2015). - Загл. с экрана.

11. Рыбкина, Н. П. К вопросу о создании музея Академии наук / Н. П. Рыбкина, В. Г. Ильинская // Фундаментальная наука: проблемы изучения, сохранения и реставрации документального наследия. - М. : Архив РАН, 2013. - С. 430-434.

\section{REFERENCES}

1. Bodrova M.L., Korneva-Chaeva I.A., Rybkina N.P. Kontseptsiya i printsipy eksponirovaniya vystavki "Dokument. Ot beresty k nauchnomu trudu" v Arkhive Rossiyskoy akademii nauk [The Conception and Principles ofDisplaying the Exhibition "Document. From Birch-Bark Letter to Scientific Work" in the Archive of Russian Academy of Sciences]. Istoricheskie, filosofskie, politicheskie i yuridicheskie nauki, kul'turologiya i iskusstvovedenie. Voprosy teorii $i$ praktiki [Historical, Philosophical, Political and Legal 
Sciences, Cultural Studies and Art History. Theory and Practice]. Tambov, Gramota Publ., 2015, no. 2 (52), part 2, pp. 35-38.

2. Ilizarov S.S. Nachala russkoy nauchnoy literatury (obosnovanie $\mathrm{v}$ trudakh Millera) [The Beginnings of the Russian Scientific Literature (Substantiation in the Writings of Miller)]. VIET (Voprosy istorii estestvoznaniya i tekhniki), 2010, no. 2, pp. 5-91.

3. Kozlov V.P. Annotatsiya [Abstract]. Istoriya pisma, dokumenta i arkhivnogo dela v Rossii: $v 3$ ch. [History of Writing, Document and Archivistics in Russia: in 3 Parts]. Moscow, 2010.

4. Kopaneva N.P. Akvareli Marii Sibilly Merian v Sankt-Peterburgskom filiale Arkhiva Rossiyskoy Akademii nauk: "Mne zakhotelos predstavit... bozhestvennoe chudo» [Watercolors by Maria Sybil Merian in Saint Petersburg Branch of the Archives of Russian Academy of Sciences: "I Wanted... to Present a Divine Miracle"]. Available at: http://www.arran.ru/ data/collections/col9_.pdf. (accessed July 20, 2015).

5. Moyst V. "Attraktsiona $u$ nas ne budet, $i$ tsiklotron v ekspozitsii ne pomestitsya”: intervyu $s$ initsiatorom sozdaniya muzeya Rossiyskoy akademii nauk, direktorom Arkhiva RAN Vitaliem Afiani ["We will have no attraction, and the exposition will not hold the cyclotron". Interview with the initiator of creation of the Museum of history of Russian Academy of Sciences, Director of Archives of RAS, Vitaly Afiani]. Available at: https:/www.gazeta.ru/culture/2013/ 08/08/a_5546897.shtml. (accessed August 13, 2013).

6. Murzintseva A.E. Muzei Rossiyskoy akademii nauk: istoriko-kulturologicheskiy analiz [Museums of Russian Academy of Sciences: Historical and Culturological Analysis]. Dslib.net: Biblioteka dissertatsiy. Biblioteka dissertatsiy $i$ avtoreferatov Rossii dslib.net [Library Dissertations and Abstracts in Russia dslib.net]. Available at: http://www.dslib.net. (accessed July 20, 2015).
7. Mironov V.V., ed. Nauchnoe iskusstvo: tezisy I Mezhdunarodnoy nauchno-prakticheskoy konferentsii, MGU im. Lomonosova, 4-5 apr. 2012 g. [Science Art. Abstracts of the 1st International Research and Practice Conference. Lomonosov Moscow State University, April 4-5, 2012]. Moscow, MIEE Publ., 2012, p. 35.

8. Nesmeyanov A.N. Pisma uchashchimsya o neobkhodimosti polucheniya obrazovaniya [Letters to Students About the Necessity of Getting an Education]. Arkhiv Rossiyskoy akademii nauk [Archive of Russian Academy of Sciences], F. 1647, Op. 1, D. 229.

9. Postanovlenie Prezidiuma RAN № 316 ot 29.04.2008 o sostoyanii $i$ dopolnitelnom finansirovanii muzeev Rossiyskoy akademii nauk [Decree of the Presidium of RAS no. 316 of April 29, 2008 on Status and Additional Funding of Museums of Russian Academy of Sciences]. Available at: http://www.ras.ru/ presidium/documents/directions.aspx $[\mathrm{ID}=3504 \mathrm{~b} 0 \mathrm{a} 0$ 851 c-4610-90be-66e1c9729 fd6\&print=1. (accessed July 25, 2015).

10. Pshenichnaya S.V. Kontseptualnaya model muzeya $\mathrm{v}$ sovremennoy otechestvennoy muzeologii [A Conceptual Model of Museum in Modern Domestic Museology]. Gosudarstvennyy muzey-pamyatnik "Isaakievskiy sobor": [sayt]. Muzei Rossii: poiski, issledovaniya, opyt raboty: sbornik nauchnykh trudov [State Museum and Monument "St. Isaac's Cathedral". Museums of Russia: Searches, Research, Experience. Collection of Scientific Papers], 2007, no. 9. Available at: http://isaak.spb.ru/digest/num9/pshen. (accessed July 22, 2015).

11. Rybkina N.P., Ilyinskaya V.G. K voprosu o sozdanii muzeya Akademii nauk [On the Creation of the Museum of Academy of Sciences]. Fundamentalnaya nauka: problemy izucheniya, sokhraneniya $i$ restavratsii dokumentalnogo naslediya [Fundamental science: problems of study, preservation and restoration of documentary heritage]. Moscow, Arkhiv RAN, 2013, pp. 430-434.

\section{Information About the Authors}

Irina A. Korneva-Chaeva, Senior Researcher, Archive of Russian Academy of Sciences, Member of Association of Art Critics, Novocheremushkinskaya St., 34, 117218 Moscow, Russian Federation, ircorn@mail.ru.

Natalya P. Rybkina, Senior Researcher, Archive of Russian Academy of Sciences, Director of Museum Group, Novocheremushkinskaya St., 34, 117218 Moscow, Russian Federation, n.rybkind@gmail.com.

\section{Информация об авторах}

Ирина Анатольевна Корнева-Чаева, ст. научный сотрудник Архива РАН, член Ассоциации искусствоведов, ул. Новочеремушкинская, 34, 117218 г. Москва, Российская Федерация, ircorn@mail.ru.

Наталья Платоновна Рыбкина, ст. научный сотрудник Архива РАН, руководитель Музейной группы, ул. Новочеремушкинская, 34, 117218 г. Москва, Российская Федерация, n.rybkind@gmail.com. 